\title{
Knowledge and beliefs about alcohol consumption, longer-term health risks, and the link with cancer in a sample of Australian adults
}

\author{
Trish Cotter $^{\mathrm{A}}$, Donna Perez, ${ }^{\mathrm{B}}$, Sally Dunlop ${ }^{\mathrm{B}, \mathrm{C}}$, \\ James Kite $^{\mathrm{B}, \mathrm{D}}$ and Clive Gaskin ${ }^{\mathrm{B}}$ \\ ${ }^{\mathrm{A}}$ Victorian Comprehensive Cancer Centre \\ ${ }^{\mathrm{B}}$ Cancer Institute NSW \\ ${ }^{\mathrm{C}}$ Sydney School of Public Health, The University of Sydney \\ ${ }^{\mathrm{D}}$ Corresponding author.Email: james.kite@cancerinstitute.org.au
}

Alcohol has a range of chronic effects on health, including cardiovascular disease, cirrhosis of the liver, diabetes and cancer. ${ }^{1-5}$ It is estimated that $5 \%$ of all cancers diagnosed each year in Australia are attributable to long-term chronic use of alcohol. ${ }^{6}$ Australian per capita consumption of alcohol is high by world standards. ${ }^{7,8}$ Current Australian guidelines for the consumption of alcohol (revised in 2009) state that there is no level of alcohol consumption that can be guaranteed as safe or risk-free and that in order to minimise the risk of alcohol-related harm (i.e. injury, disease and death), healthy men and women should not drink more than two standard drinks on any day. ${ }^{9}$ This represents a downward revision for men (from four to two drinks a day) from the previous guidelines. ${ }^{10}$ Furthermore, the guidelines state that drinking less frequently over a lifetime (e.g. drinking weekly rather than daily) considerably reduces the risk of alcohol-related harm and disease.

A UK study conducted in 2009 found that only 14\% of adults recognised alcohol consumption as a cancer risk factor ${ }^{11}$ but, to date, there has been very little published Australian research investigating public knowledge of the link between alcohol and longer-term health risks. ${ }^{12}$ This study aimed to assess the public's: (a) understanding regarding 'safe' levels of alcohol consumption in relation to minimising the risks of longer-term alcohol-related harm; (b) knowledge and beliefs about the longer-term risks of alcohol consumption; and (c) recognition of personal longer-term health risks from alcohol consumption.

\section{Methods}

Data were drawn from the 2009 Cancer Institute New South Wales (NSW) Lifestyle and Cancer Survey, a telephone survey of NSW adults (aged 18 years and over) conducted to monitor beliefs, attitudes and behaviours relating to cancer preventive lifestyle factors. Households were recruited through list-assisted random digit dialling (of landline telephone numbers only) and a random selection procedure was used for selecting a participant within the household. An overall response rate of $15 \%$ was achieved (American Association for Public Opinion Research response rate \#4). ${ }^{13}$ This survey contained multiple modules on lifestyle behaviours and cancer with a total sample size of 1508; analyses for this paper were limited to the participants who responded to questions from the module on alcohol $(n=1255)$. Sample 
demographics are shown in Table 1. Data were weighted for the probability of selection, based on the age and gender distribution of the NSW population. ${ }^{14}$

\section{Measures}

\section{Alcohol consumption}

All participants were asked how often they drank alcohol (at least once a week, less than once a week, I don't drink alcohol) and, if they drank at all, how many standard drinks they would usually consume during a typical drinking occasion. A standard drink was defined for participants as one middy ( $285 \mathrm{mls}$ ) of full-strength beer, one schooner (425 mls) of light beer, one small glass (or standard serve) of wine $(100 \mathrm{mls})$, or one pub-sized nip $(30 \mathrm{mls})$ of spirits. Those who drank at least once a week (hereafter 'weekly

Table 1. Sample characteristics, participants for alcohol module, Cancer Institute NSW Lifestyle and Cancer Survey, 2009, unweighted

\begin{tabular}{lc}
\hline & $\begin{array}{c}\text { Total sample }(n=1255) \\
n(\%)^{\mathrm{a}}\end{array}$ \\
\hline $\begin{array}{l}\text { Gender } \\
\text { Male }\end{array}$ \\
$\quad$ Female & $604(48.2)$ \\
Age (years) & $650(51.8)$ \\
$18-29$ & \\
$30-44$ & $262(21.2)$ \\
$45-64$ & $341(27.5)$ \\
$65+$ & $401(32.3)$ \\
Income & $235(19.0)$ \\
$<\$ 40000$ & \\
$\quad \$ 40000-\$ 80$ 000 & $347(32.0)$ \\
$>\$ 80$ 000 & $295(27.2)$ \\
Education & $443(40.8)$ \\
$<$ High school & \\
High school & $273(21.9)$ \\
Tertiary & $528(42.3)$ \\
Household includes children & $447(35.8)$ \\
No & \\
Yes & $760(60.7)$ \\
\hline Proportion of those who responded to the question.
\end{tabular}

drinkers') were also asked on how many days they would drink during a typical week. To facilitate analysis, weekly drinkers were grouped into four categories based on the current Australian guidelines according to their frequency and level of consumption (Table 2).

Knowledge relating to 'safe' levels

of alcohol consumption

Participants were asked the maximum number of standard drinks an adult male/female could have on any day without significantly increasing their risk of health problems in the longer term.

Knowledge and beliefs about health effects of alcohol consumption

All participants were asked whether they thought cancer, heart disease, diabetes, high cholesterol, liver problems, digestive problems, and overweight/obesity could result from drinking too much alcohol. They were also asked whether they agreed that "Regular moderate alcohol consumption can have serious health consequences in the long term" ( $1=$ disagree strongly to $5=$ agree strongly; dichotomised into agree strongly/somewhat vs other) and "Limiting your alcohol intake helps prevent cancer" (agree strongly/somewhat vs other).

\section{Perceptions of personal risk from alcohol consumption}

Participants were asked if they agreed with the following statements: "I should be drinking less alcohol than I currently drink" (agree strongly/somewhat vs other), and "What do you think is the likelihood of becoming seriously ill from your drinking if you continue to drink alcohol at your current level?" (definitely/probably will vs other).

\section{Covariates}

Covariates of interest were gender, age, household income, education, and whether there were any children aged 17 years and under living in the household.

\section{Statistical analyses}

Chi-squared analyses were conducted to examine sociodemographic differences between weekly drinkers and

Table 2. Categories of participants who drank at least once a week ('weekly drinkers') according to frequency and level of alcohol consumption, Cancer Institute NSW Lifestyle and Cancer Survey, 2009

\begin{tabular}{llll}
\hline & & $\begin{array}{c}\text { Frequency of alcohol consumption } \\
\text { Drinks } \\
\text { Drinks }\end{array}$ & $\begin{array}{c}\text { Drink } \\
\text { 4-7 days/week }\end{array}$ \\
\hline $\begin{array}{c}\text { Typical level of } \\
\text { alcohol consumption }\end{array}$ & $\begin{array}{c}\text { Drinks within recommended guidelines } \\
(<=2 \text { standard drinks a day }) \\
\text { Drinks above guidelines } \\
(>2 \text { standard drinks a day })\end{array}$ & Category A & Category B \\
& Category C & Category D \\
\hline
\end{tabular}


non-drinkers, and between weekly drinker categories. Multiple logistic regression analyses were used to determine associations between the levels of drinking and the following outcomes: (a) knowledge of the current guidelines for alcohol consumption; (b) knowledge about the long-term health risks of moderate alcohol consumption; (c) recognition that alcohol can cause cancer; (d) belief that limiting alcohol intake helps prevent cancer; (e) belief that they should be drinking less than current consumption; and (f) belief that they could become seriously ill from current drinking. For each of these outcomes, two analyses including all covariates were conducted. The first included the full sample while the second used only the sample of weekly drinkers. The analyses were generated using SAS (version 9.2, SAS Institute, Cary, NC).

\section{Results}

\section{Alcohol consumption}

Almost half of all participants drank alcohol at least once per week while $22 \%$ reported that they did not drink alcohol at all (Table 3). Over half the men were weekly drinkers, compared to $40 \%$ of women. Those participants aged 45-64 years, tertiary educated, high income, or with no children in their household were more likely to be weekly drinkers.
The proportion of all drinkers who were drinking above the current guidelines was $37 \%$. Of the weekly drinkers, $43 \%$ were drinking above the guidelines (Categories $\mathrm{C}$ and D). Over half of the men who drank at least weekly were drinking above the guidelines, as were over three-quarters of those aged 18-29 years. The greatest proportion of tertiary educated participants were in Category A (i.e. drinking within the recommended guidelines), while around half of participants with lower levels of education were drinking above the guidelines (Categories $\mathrm{C}$ or D).

\section{Correct knowledge of Australian guidelines}

Sixty-seven percent of participants correctly nominated the maximum number of standard drinks per day that met the current Australian guidelines; that is, between zero and two. Drinkers were less likely to know the correct amount that meets the guidelines than non-drinkers (Table 4). In addition, those drinking above the guidelines (Category $\mathrm{C}$ and D) were less likely to know the guidelines than those in Category A (Table 5).

\section{Long-term harms of alcohol consumption}

Approximately two-thirds (64\%) of participants agreed that regular moderate alcohol consumption can have

Table 3. Current alcohol consumption by socio-demographic indicators, Cancer Institute NSW Lifestyle and Cancer Survey, 2009

\begin{tabular}{|c|c|c|c|c|c|c|c|c|c|}
\hline & \multicolumn{4}{|c|}{ Total sample $(n=1255)$} & \multicolumn{5}{|c|}{ Weekly drinkers $(n=646)$} \\
\hline & $\begin{array}{l}\text { Never } \\
(\%)\end{array}$ & $\begin{array}{c}\text { Less than } \\
\text { weekly } \\
(\%)\end{array}$ & $\begin{array}{l}\text { Weekly } \\
\text { (\%) }\end{array}$ & p-value & $\begin{array}{c}\text { Category A } \\
(\%)\end{array}$ & $\begin{array}{c}\text { Category B } \\
(\%)\end{array}$ & $\begin{array}{c}\text { Category C } \\
(\%)\end{array}$ & $\begin{array}{c}\text { Category D } \\
(\%)\end{array}$ & $p$-value \\
\hline Total & 22.0 & 29.6 & 48.4 & - & 33.2 & 24.1 & 24.1 & 18.6 & - \\
\hline \multicolumn{10}{|l|}{ Gender } \\
\hline Male & 14.8 & 28.1 & 57.2 & & 24.7 & 21.4 & 32.9 & 21.1 & \\
\hline Female & 28.6 & 31.0 & 40.4 & $<0.01$ & 40.7 & 22.0 & 25.7 & 11.6 & $<0.01$ \\
\hline \multicolumn{10}{|l|}{ Age (years) } \\
\hline $18-29$ & 26.2 & 34.4 & 39.4 & & 15.9 & 8.6 & 65.5 & 10.0 & \\
\hline $30-44$ & 19.0 & 35.8 & 45.2 & & 36.5 & 13.1 & 35.7 & 14.7 & \\
\hline $45-64$ & 18.8 & 24.4 & 56.9 & & 33.5 & 22.1 & 22.9 & 21.5 & \\
\hline $65+$ & 28.2 & 23.3 & 48.5 & $<0.01$ & 30.5 & 45.3 & 7.0 & 17.2 & $<0.01$ \\
\hline \multicolumn{10}{|l|}{ Income } \\
\hline$<\$ 40000$ & 32.4 & 30.5 & 37.1 & & 29.9 & 23.9 & 31.5 & 14.8 & \\
\hline$\$ 40000-\$ 80000$ & 22.1 & 31.2 & 46.7 & & 33.4 & 21.7 & 27.9 & 17.1 & \\
\hline$>\$ 80000$ & 12.7 & 26.5 & 60.9 & $<0.01$ & 30.2 & 19.2 & 33.8 & 16.8 & 0.85 \\
\hline \multicolumn{10}{|l|}{ Education } \\
\hline$<$ High school & 31.9 & 26.8 & 41.4 & & 26.9 & 26.6 & 22.4 & 24.1 & \\
\hline High school & 19.5 & 32.3 & 48.2 & & 24.7 & 19.1 & 39.2 & 17.0 & \\
\hline Tertiary & 18.4 & 28.3 & 53.3 & $<0.01$ & 40.6 & 21.8 & 23.6 & 13.9 & $<0.01$ \\
\hline \multirow{2}{*}{\multicolumn{10}{|c|}{$\begin{array}{l}\text { Household } \\
\text { includes children }\end{array}$}} \\
\hline & & & & & & & & & \\
\hline No & 22.8 & 26.7 & 50.5 & & 30.1 & 26.9 & 24.7 & 18.3 & \\
\hline Yes & 20.6 & 34.0 & 45.4 & 0.02 & 33.7 & 12.8 & 38.7 & 14.8 & $<0.01$ \\
\hline
\end{tabular}


Table 4. Correct knowledge of the alcohol guidelines, attitudes towards the long-term harms of alcohol consumption and perceived personal risk, by alcohol consumption (all participants), Cancer Institute NSW Lifestyle and Cancer Survey, 2009

\begin{tabular}{|c|c|c|c|c|c|c|c|c|c|c|}
\hline & \multirow{2}{*}{$\begin{array}{c}\text { Total sample } \\
(n=1255) \\
\%\end{array}$} & \multicolumn{3}{|c|}{$\begin{array}{c}\text { Never } \\
(n=224)\end{array}$} & \multicolumn{3}{|c|}{$\begin{array}{l}\text { Less than weekly } \\
\qquad(n=295)\end{array}$} & \multicolumn{3}{|c|}{$\begin{array}{c}\text { Weekly } \\
(n=564)\end{array}$} \\
\hline & & $\%$ & OR & $\mathrm{Cl}$ & $\%$ & OR & $\mathrm{Cl}$ & $\%$ & OR & $\mathrm{Cl}$ \\
\hline $\begin{array}{l}\text { Correct knowledge of recommendations } \\
\text { (0-2 standard drinks/day) }\end{array}$ & 67 & 84 & 1 & - & 73 & $0.51^{* *}$ & $0.32-0.83$ & 57 & $0.25^{* *}$ & $0.16-0.39$ \\
\hline $\begin{array}{l}\text { Regular moderate alcohol consumption } \\
\text { can have serious health consequences } \\
\text { in the long term (agree) }\end{array}$ & 64 & 83 & 1 & - & 69 & $0.44^{* *}$ & $0.29-0.68$ & 59 & $0.35^{* *}$ & $0.23-0.52$ \\
\hline Alcohol can cause cancer (agree) & 48 & 53 & 1 & - & 49 & 1.10 & $0.78-1.57$ & 52 & 1.01 & $0.73-1.41$ \\
\hline $\begin{array}{l}\text { Limiting your alcohol intake helps } \\
\text { prevent cancer (agree) }\end{array}$ & 51 & 54 & 1 & - & 56 & 0.92 & $0.64-1.31$ & 49 & $0.69 *$ & $0.50-0.97$ \\
\hline $\begin{array}{l}\text { I should be drinking less than I currently } \\
\text { drink (agree) - all drinkers only }(n=857)\end{array}$ & 36 & $\mathrm{n} / \mathrm{a}$ & $\mathrm{n} / \mathrm{a}$ & $\mathrm{n} / \mathrm{a}$ & 21 & 1 & - & 47 & $4.00^{* *}$ & $2.85-5.61$ \\
\hline $\begin{array}{l}\text { I am likely to become seriously ill from } \\
\text { my current drinking (definitely/probably } \\
\text { will) - all drinkers only }(n=859)\end{array}$ & 14 & $\mathrm{n} / \mathrm{a}$ & $\mathrm{n} / \mathrm{a}$ & $\mathrm{n} / \mathrm{a}$ & 9 & 1 & - & 17 & $2.56^{* *}$ & $1.61-4.07$ \\
\hline
\end{tabular}

Table 5. Correct knowledge of the alcohol guidelines, attitudes towards the long-term harms of alcohol consumption and perceived personal risk, by alcohol consumption (weekly drinkers only), Cancer Institute NSW Lifestyle and Cancer Survey, 2009

\begin{tabular}{|c|c|c|c|c|c|c|c|c|c|c|c|c|}
\hline & \multicolumn{12}{|c|}{ Weekly drinkers $(n=564)$} \\
\hline & \multicolumn{3}{|c|}{ Category A } & \multicolumn{3}{|c|}{ Category B } & \multicolumn{3}{|c|}{ Category C } & \multicolumn{3}{|c|}{ Category D } \\
\hline & $\%$ & OR & $\mathrm{Cl}$ & $\%$ & OR & $\mathrm{Cl}$ & $\%$ & OR & $\mathrm{Cl}$ & $\%$ & OR & $\mathrm{Cl}$ \\
\hline $\begin{array}{l}\text { Correct knowledge of recommendations } \\
(0-2 \text { standard drinks/day) }\end{array}$ & 71 & 1 & - & 57 & 0.63 & $0.37-1.06$ & 54 & $0.56^{*}$ & $0.34-0.92$ & 36 & $0.27^{* *}$ & $0.15-0.49$ \\
\hline $\begin{array}{l}\text { Regular moderate alcohol consumption } \\
\text { can have serious health consequences } \\
\text { in the long term (agree) }\end{array}$ & 61 & 1 & - & 51 & 0.72 & $0.44-1.18$ & 73 & 1.53 & $0.94-2.49$ & 41 & $0.46^{* *}$ & $0.27-0.79$ \\
\hline Alcohol can cause cancer (agree) & 53 & 1 & - & 56 & 1.04 & $0.64-1.70$ & 44 & 1.34 & $0.84-2.12$ & 60 & 0.85 & $0.50-1.46$ \\
\hline $\begin{array}{l}\text { Limiting your alcohol intake helps } \\
\text { prevent cancer (agree) }\end{array}$ & 48 & 1 & - & 44 & 1.07 & $0.65-1.78$ & 54 & 1.00 & $0.63-1.59$ & 46 & 1.04 & $0.60-1.78$ \\
\hline $\begin{array}{l}\text { I should be drinking less than } \\
\text { I currently drink (agree) }\end{array}$ & 28 & 1 & - & 52 & $4.18^{* *}$ & $2.44-7.19$ & 49 & $2.23^{* *}$ & $1.36-3.63$ & 73 & $9.42^{* *}$ & $5.09-17.45$ \\
\hline $\begin{array}{l}\text { I am likely to become seriously ill } \\
\text { from my current drinking (definitely/ } \\
\text { probably will) }\end{array}$ & 11 & 1 & - & 12 & 1.28 & $0.59-2.74$ & 19 & 1.38 & $0.70-2.72$ & 32 & $4.25^{* *}$ & $2.10-8.60$ \\
\hline
\end{tabular}

serious health consequences in the longer term. Drinkers were less likely to agree than non-drinkers. Similarly, Category D drinkers were less likely to agree than Category A drinkers.

Only $48 \%$ of participants were aware that drinking too much alcohol could cause cancer. Participants' awareness varied in relation to the effect of alcohol on heart disease (79\%), diabetes (70\%), high cholesterol (54\%), liver problems (98\%), digestive problems (76\%), and being overweight or obese $(89 \%)$. There were no significant differences between drinkers and non-drinkers, or between any of the weekly drinker categories, in relation to knowledge of the causal link between alcohol and cancer. 
Further, half of the participants agreed that limiting alcohol intake helps prevent cancer (51\%). Weekly drinkers were less likely than non-drinkers to agree.

\section{Perceived personal risk}

Just over one-third of drinkers agreed that they should be drinking less than they currently drink (36\%). Weekly drinkers were four times more likely than occasional drinkers to agree that they should be drinking less. Category $\mathrm{B}, \mathrm{C}$ and $\mathrm{D}$ drinkers were similarly more likely to agree than Category A drinkers.

Weekly drinkers were over two times more likely to believe they would become seriously ill from their current drinking than occasional drinkers. Category D drinkers were more likely to agree with this statement than those in Category A.

\section{Discussion}

These results suggest a substantial knowledge deficit among many adults in relation to the current recommendations for alcohol consumption, as well as the link between longer-term health risks and moderate alcohol consumption. There is a clear need to address alcohol consumption, particularly among those aged 18-44 years, those with lower levels of education, and men.

There is evidence that, while many national health organisations have guidelines for moderate alcohol consumption, people in these countries either do not know or are confused by these guidelines. ${ }^{12,15,16}$ Despite the fact that approximately two-thirds of the sample correctly nominated the amount that met the recommended guidelines for alcohol consumption, drinkers were generally less likely to correctly identify the recommendations, as were those weekly drinkers who drank above the guidelines. While it is important to note that these findings may have been influenced by the introduction of current guidelines in the same year as the survey, they still suggest a need to increase awareness of the current guidelines for alcohol consumption.

Of concern was that, despite mounting evidence, about one-third of the sample did not agree that regular moderate alcohol consumption can have serious health consequences in the long term. Furthermore, there was an association between alcohol consumption and recognition of the longer-term impact of drinking, suggesting either a knowledge deficit in drinkers, especially heavier drinkers, or self-exempting beliefs, in that drinkers are less likely to want to recognise that their behaviour is putting them at risk. The implication from either of these scenarios would be that increasing the awareness and belief of these drinkers of the long-term health consequences of their drinking would be an important component in a strategy to reduce consumption.
In our study, participants' definition of 'moderate drinking' was not assessed. Other research has identified some confusion over what constitutes 'moderate' drinking ${ }^{16}$ and that heavier drinkers have been found to have an inflated definition of moderate drinking. ${ }^{17}$ In our study, while the heaviest drinkers were the most likely to recognise that they should drink less than they currently drink, it may be that even if these heavier drinkers reduced consumption to what they perceive as 'moderate', it may not be to a level sufficient to significantly reduce their risk of long-term harm. Future research should investigate the public's understanding of 'moderate drinking'.

Our findings also suggest that recognition of cancer as a possible long-term consequence of alcohol is also an issue to address and add weight to existing evidence that understanding of cancer risk from alcohol consumption is poor. ${ }^{18}$ It is possible that public knowledge of long-term harms of alcohol consumption may be confounded by some evidence suggesting beneficial effects of alcohol. ${ }^{16}$ This is despite the fact that the clinical consensus is that people do not need to take up or maintain drinking for health benefits since alternative means of preventing heart and vascular disease are available. ${ }^{7}$ There is therefore scope for further research exploring cancer as a motivator to reduce or abstain from alcohol consumption.

A major limitation of the study is the low response rate. This was impacted by a short fieldwork period (3 weeks) prior to the launch of a campaign and therefore an inability in many cases to contact the randomly selected adult in the household. Additionally, the length of the survey (approx. 26 mins) may have acted as a deterrent for some potential respondents. Despite our sample having more tertiary educated people than would be expected compared to the NSW population, ${ }^{19}$ the levels of alcohol consumption in this sample correspond closely to the levels reported in more representative studies. ${ }^{20}$ Secondly, this study relied on self-reported alcohol consumption, which may be subject to recall bias, especially as most alcoholic beverages are not served as the equivalent of one standard drink. This means that participants may have significantly underreported their actual consumption if they simply reported how many drinks they usually consume, rather than calculating the number of standard drinks. Participants' understanding of the term 'standard drink' was not assessed in this survey but there is some evidence from other studies showing that understanding of a standard drink is often poor and that, as a result, drinks are commonly over-poured and consumption underreported. ${ }^{21,22}$

\section{Conclusion}

Our results validate the need for continued efforts to reduce alcohol consumption among adults. New initiatives should target those aged 18-44 years, men, and those with lower levels of education. Implementation of well-resourced 
public education initiatives would be expected to contribute to a reduction in the burden of cancer and other alcohol-related disease.

\section{Acknowledgments}

The authors would like to acknowledge Julie Denney and Jenny Crawford from the Ipsos-Eureka Social Research Institute for their work in the implementation and management of the survey, as well as providing initial analysis and reporting on the survey results. We would also like to thank David Roder and Anne Cust for reviewing a draft of this paper and providing valuable feedback.

\section{References}

1. World Health Organization. Global status report on alcohol and health. WHO; Geneva: 2011.

2. Danaei G, Vander Hoorn S, Lopez AD, Murray CJ, Ezzati M; Comparative Risk Assessment collaborating group. (Cancers). Causes of cancer in the world: comparative risk assessment of nine behavioural and environmental risk factors. Lancet 2005; 366(9499): 1784-93. doi:10.1016/S0140-6736(05)67725-2

3. Lewis S, Campbell S, Proudfoot E, Weston A, Cotter T, Bishop JF. Alcohol consumption and cancer risk. Cancer Institute NSW: Sydney; 2007.

4. World Cancer Research Fund/American Institute for CancerResearch. Food, Nutrition, Physical Activity, and the Prevention of Cancer: a Global Perspective. AICR: Washington DC; 2007.

5. International Agency for Research on Cancer. Working Group on the Evaluation of Carcinogenic Risks to Humans. Alcohol drinking. In: IARC monographs on the evaluation of carcinogenic risks to humans. International Agency for Research on Cancer: Lyon. 1988; p. 1-378.

6. Winstanley MH, Pratt IS, Chapman K, Griffin HJ, Croager EJ, Olver IN et al. Alcohol and cancer: a position statement from Cancer Council Australia. Med J Aust 2011; 194(9): 479-82.

7. National Preventative Health Taskforce. Australia: the healthiest country by 2020. Technical Report No 3: Preventing alcoholrelated harm in Australia: a window of opportunity. Commonwealth of Australia: Canberra; 2009.

8. Organisation for Economic Co-operation and Development (OECD). OECD health data: statistics and indicators for 30 countries. OECD: Paris; 2009.

9. National Health and Medical Research Council. Australian guidelines to reduce health risks from drinking alcohol. NHMRC: Canberra; 2009.
10. National Health and Medical Research Council. Australian Alcohol Guidelines: Health Risks and Benefits. NHMRC: Canberra; 2001.

11. Sanderson SC, Waller J, Jarvis MJ, Humphries SE, Wardle J. Awareness of lifestyle risk factors for cancer and heart disease among adults in the UK. Patient Educ Couns 2009; 74(2): 221-7. doi:10.1016/j.pec.2008.08.003

12. Australian Institute of Health \& Welfare. 2004 National Drug Strategy Household Survey: detailed findings. AIHW: Canberra; 2005.

13. American Association for Public Opinion Research (AAPOR). Standard definitions: final dispositions of case codes and outcome rates for surveys. AAPOR: Lenexa, Kansas; 2011.

14. Australian Bureau of Statistics. Population by age and sex, Australian states and territories, June 2006. ABS: Canberra; 2007.

15. Lader D, Goddard E. Drinking: adults' behaviour and knowledge in 2006. Office for National Statistics: London; 2006.

16. Green CA, Polen MR, Janoff SL, Castleton DK, Perrin NA. "Not getting tanked": definitions of moderate drinking and their health implications. Drug Alcohol Depend 2007; 86(2-3): 265-73. doi:10.1016/j.drugalcdep.2006.07.002

17. Ogborne AC, Smart RG. Public opinion on the health benefits of moderate drinking: results from a Canadian National Population Health Survey. Addiction 2001; 96(4): 641-9. doi:10.1046/ j.1360-0443.2001.96464113.x

18. Miles A, Redeker C, Pouli N. Beliefs about the level of smoking, alcohol intake and body mass index required to increase cancer risk. Prev Med 2010; 51(3-4): 340-1. doi:10.1016/j.ypmed. 2010.06.014

19. Australian Bureau of Statistics. 2011 Census. Available at: http://www.censusdata.abs.gov.au/census_services/getproduct/ census/2011/quickstat/1?opendocument\&navpos=220 (Cited 4 September 2013).

20. Australian Institute of Health \& Welfare. 2007 National Drug Strategy Household Survey: detailed findings. AIHW: Canberra; 2008.

21. Carruthers SJ, Binns CW. The standard drink and alcohol consumption. Drug Alcohol Rev 1992; 11(4): 363-70. doi:10.1080/09595239200185491

22. White AM, Kraus CL, Flom JD, Kestenbaum LA, Mitchell JR, Shah K et al. College students lack knowledge of standard drink volumes: implications for definitions of risky drinking based on survey data. Alcohol Clin Exp Res 2005; 29(4): 631-8. doi:10.1097/01.ALC.0000158836.77407.E6 